\title{
Taxonomic studies on Idiocerini Leafhoppers (Hemiptera: Cicadellidae: Eurymelinae: Idiocerini) of Sri Lanka
}

\author{
R. Gnaneswaran \\ Department of Zoology, University of Jaffna, Sri Lanka \\ Email: rajignanes@yahoo.com
}

\begin{abstract}
Seven species of Leafhoppers belong to the tribe: Idiocerini of Subfamily Eurymelinae in Family Cicadellidae, are reported from Sri Lanka based on the field study. Four species of Idioscopus, and each one species of genera Amritotus, Busoniomimus and Jogocerus were described with their distribution in the country. Busoniomimus manjunathi Viraktamath and Viraktamath and Jogocerus freytagi were described for the first time from Sri Lanka.
\end{abstract}

Keywords—Idiocerini, Busoniomimus, Jogocerus, Idioscopus

\section{INTRODUCTION}

Eurymelinae is one of the largest subfamily of arboreal leafhoppers. Species of this group feed on a wide variety of trees and shrubs, including several of economic importance with some considered agricultural pests (Fletcher \& Dangerfield, 2002; Gnaneswaran et al., 2007). This group is distributed worldwide and includes more than 1300 species in 174 genera in 11 tribes. Based on the phylogenetic analysis with molecular and morphological characteristics, the expanded concept of Eurymelinae (Dietrich \& Thomas, 2018) was confirmed and six more monophyletic groups are recognized as new tribes and status of Idiocerini is redefined by Xue, et al., 2020.

Tribe Idiocerini was earlier placed as Subfamily Idiocerniae of family Cicadellidae, now confirmed as one of the tribe in Subfamily Eurymelinae, includes the species of 59 genera (Xue, et al., 2020). They distributed Aftrotropical, Australian, Madagascar, Nearctic, Oriental and Palaearctic regions.

Among 06 genera reported from Sri Lanka, under subfamily Idiocerinae, three genera namely Lankacerus Viraktamath, Neoscopus Viraktamath and Ceylonoscopus Viraktamath are now placed in tribe- Megipocedrini Isaeve of Sub Family Eurymelinae. Likewise, genus Balocha Distant is now placed in the tribe, Balocerini of the same subfamily. But, Amritodus Anufriev, Idioscopus Baker and Periacerus Viraktamath \& Parvathi are included in the Tribe Idiocerini (Xue, et al., 2020).

\section{Idiocerini Baker}

Idiocerini Baker, 1915: 317. Type genus: Idiocerus Lewis, 1834:47, original designation.

Idiocerinae Baker: Evans, 1934:140

Idiocerini Baker: Xue, et.al., 2020:698
The tribe Idiocerini is a moderately large group of leafhoppers which shows cosmopolitan distribution. The members of this tribe are small to medium-sized wedge shaped with short broad vertex that is rounded to the front; face is broad. Lateral frontal sutures are extending to ocelli; ocelli on face; distance between ocelli is less than distance between antennal pits. Antennae are moderately long and the flagellum often with disc in males. Crown is short and broad usually striate; the pronotum does not extend beyond eyes; forewing with two or three subapical cells; Appendix developed and bordering two apical cells; hind femur with setal formula $2+0$ or $2+1$; subgenital plate broadened in lateral view, depressed in ventral view; style sickle-shaped, usually without pre apical lobe, often with fine or stout pre apical setae on dorsal margin; aedeagus tube-like, usually with paired processes, dorsal apodeme usually developed, gonopore on ventral margin apical or subapical (Xue, at.al., 2020).

The first Idiocerini leafhopper from Sri Lanka was discovered by Melichar (1903). He described six species under Genus Idiocerus Lewis and all those species have now been transferred to other genera by subsequent workers. Later Distant (1908 and 1916) treated three species from the Indian Subcontinent in the genera Idiocerus Lewis.

When this study was planned to explore the members of Idiocerini in Sri Lanka, the Tribe was represented by only 05species of 03 genera (Melichar, 1903, Distant, 1908; Viraktamath, and Parvathi, 2002, Viraktamath, 2007 and Gnaneswaran, et al., 2007).

\section{MATERIALS AND METHODOLOGY}

Adult leafhoppers collected in the field by sweep netting and preserved in dry method at the Museum, were processed to study their taxonomically important morphologic characteristics such as head sutures, wing venation, hind leg spinulation and genitalia of male and female (Knight, 1965). Character states were examined the specimens under a 
stereomicroscope. The dissected genitalia were stored in a micro vial with fresh glycerol and pinned below the specimen from which the abdomen was removed.

Repositories: The specimens collected at the field from 2006 -2021 have been deposited in the Entomological museums of Department of Zoology, University of Jaffna, Sri Lanka, and of Department of Agriculture Biology, University of Peradeniya, Sri Lanka, have been used in this work.

\section{RESULTS AND DISCUSSION}

A total of 07 species belonging to 4 genera were found from field collections made in 17 districts of the country. They are Busoniomimus manjunathi, Jogocerus feytagi. Idioscopus unimaculatus I.nagpurensis, I. clypealis, I. nitidulus, and Amritodus brevistylus, The distribution of all species and the morphological characteristics of first three species are described in this paper, with illustrations. The rest four species have already been reported as pests of mango in Sri Lanka (Gnaneswaran et.al., 2017).

Taxonomic information on the genera and species reported in Sri Lanka

Busoniomimus Maldonado1977

\section{A. Genus Busoniomimus Maldonado1977}

Busoniomimus Maldonado, 1977:491

Genus Busoniomimus was established by Maldonado Capriles (1977) with Idiocerus minor Biermanas type species. It consists 05 species with two: $B$. manjunathi Viraktamath and Viraktamath and $B$. mudigerensis (Viraktamath, 1976), have been known from India and Busoniomimus minor (Bierman, 1908) in Indonesia $B$. mindanaensis (Baker) -in the Philippine B. setulistylus Viraktamath and Murphy- in Singapore.

The genus is characterized by transversely striate vertex, long labium reaching to or beyond hind coxae, two anteapical cells which is either closed or open behind; Pygofer with a ventral triangulate lobe on each side, posterior margin of pygofer with or without an internal process, stem of the connective longer, aedeagal shaft postulate.

Remarks: In this study B. manjunathi was collected from Kandy district and recorded for the first time from Sri Lanka.

\section{Busoniomimus manjunathi Viraktamath and Viraktamath (Plate:1-f, vi and Plate:2- f,vi) \\ Busoniomimus manjunathi Viraktamath and Viraktamath, 1985:305}

Colouration: As described by Viraktamath and Viraktamath (1985)

Structure: vertex wide, 3.6 times wider than its length; face transversely rugulosedorsad of ocelli, rest of the face shagreened. Frontoclypeus convex; clypellus widened apically. Labium long; extending up to hind coxae. Pronotum and scutellum are shagreened. Pronotum 2.47 times wider than its length. Scutellum is (x 2) longer than the pronotum. Fore wing veins margined by circular pits on either side in their basal half. Those pits being more prominent along claval veins; two subapical cells with closed outer one.

Male genitalia: Male pygofer elongate and caudally angularly pointed with a long single ventral processes and an angular projection on ventral margin. Tenth segment with ventrally directed process; male genital plate widened distally with long hair-like marginal setae. Style is robust; connective longer than wide, wider at base. Aedeagus with a strongly developed basal strut, dorsal apodeme short arising almost in the middle of aedeagus, shaft is smoothly curved dorsally and much narrowed beyond gonopore. Apical 1/3 of the shaft postulate and a pair of caudally directed processes arise at base of shaft. Gonopore is sub apical.

Measurements: Male $3.9 \mathrm{~mm}$ long; $1.27 \mathrm{~mm}$ wide across eyes

Material examined: SRI LANKA: MCWZ: 1 male, Hanguranketa 20 x.2007.

Collectors: RGnaneswaran

Distribution:Sri Lanka (Hanguranketa) and India

Host plants : Clove (Sri Lanka), Garcinia combogia (Mercikutty et al., 2002); Garcinia gummi-gutta

(Mathew,2005)

\section{B. Jogocerus Viraktamath 1979}

Viraktamath (1979) described the genus Jogocerus with Jogocerus freytagi Viraktamath as its type species from India. He discussed its relationship with other idiocerines as "Jogocerus resembles Tasnimocerus Ghauri in the shape of pronotum which is transversely rugose, but differs from it in having a narrow based clypellus and by its distinct male genitalia. It shares the character of ventral pygoferal process with Amritodes Anufriev. But the transversely rugulose pronotum, U-shaped aedeagus, distally excavate connective distinguishes it".

Genus Jogocerus Viraktamath. Jogocerus Viraktamath, 1979:17

Type species Jogocerus freytagi Viraktamath, 1979 by original description.

Head distinctly wider than pronotum. Vertex, Pronotum, Scutellum and face dorsad of ocelli finely transversely rugose. Face including eyes wider than long. Clypellus projecting beyond genae, gradually widened distally and truncate. Pronotum about half as long as broad. Scutellum slightly longer than pronotum forewing with four apical cells and 2 or 3 subapical cells. $\mathrm{r}-\mathrm{m}$ cross vein present. Moderately broad, hind femora with setal formula $2+1$, crown with black spot on either side of median line, scutellum with basal triangle black (Viraktamath, 1979). 
Male pygofer with or without well-developed dorsal apodemes and collar process and ventral pygofer process. Sub genital plates elongate, narrow with a few like- setae. Style with apophysis elongate, curved laterally without macrosetae on outer margin connective with anterior half broad, caudal half with ' $U$ ' shaped excavation caudally. Aedeagus with well-developed dorsal apodeme with pair of lateral processes arising sub apically. Gonopore sub apical on ventral margin.

VII sternum convexly produced posterior margin of median area narrowly concave in ventral view. $2^{\text {nd }}$ valvula regularly broadened in lateral view, bearing approximately 23-25 teeth along dorsal margin.

Remarks: This genus represented by two species namely Jogocerus freytagi Viraktamath, from India (Viraktamath, 1979) and Jogocerus hainanensis Zang and Li from China (Zhang and Li, 2008). During this study both male and female specimens of $J$. freytagi were collected for the first time from Sri Lanka.

Jogocerus freytagi Viraktamath(Plate:1-g, 7 and Plate:2$\mathrm{g}, 7)$

Jogocerus freytagiViraktamath, 1979:17

Coloration: Similar to the type species described by Viraktamath (1979). Greenish yellow when fresh; two round spots on vertex, two triangles at basal angles of scutellum black; two smaller round spots on meso sternum and two other smaller spots below the them. Abdomen greenish yellow. eyes dark brown or black.

Structure: Head 1.12 times wider than pronotum in male and 1.17 times in female. vertex, pronotum, scutellum and face, dorsad of ocelli transversely striated. Face including eyes 1.2 times wider than long. clypellus extending beyond genae, gradually widened distally and truncate. Pronotum 2.1 times broader than its length. and 3.4 times longer than median length of vertex. Scutellum slightly longer than pronotum forewings with four apical cells and 3 sub apical cells, r-m cross vein present. Moderately broad, hind femora with setal formula $2+1$ crown with black spot on either side of median line, scutellum with basal triangle black.

Male genitalia: Pygofer with well-developed dorsal apodemes and collar process and ventral pygofer process, Sub genital plates elongate, narrow with a few hair likesetae .Style with apophysis elongate almost as long as genital plate, curved dorso-caudaly, with serrated ventral margin. Connective as in aedeagus with well-developed dorsal apodeme of 2/3 length of the shaft. Shaft with pair of lateral processes arising sub apically. Each process with a lateral short tooth. Gonopore sub apical.

Female : Ovipostior extending beyond the pygofer. Hind margin of the seventh sternite convexly produced and projecting beyond the pygofers. Second pair of gonapophysis with series of denticles restricted to caudal $1 / 2$ of the length.
Measurements: Male $4.56 \mathrm{~mm}$ long; $1.66 \mathrm{~mm}$ wide across eyes. Female $5.56 \mathrm{~mm}$ long; $1.78 \mathrm{~mm}$ wide across eyes.

Material examined: SRI LANKA: LCIZ 2 males, 1 female Ibbagamuwa, 23 xi.2007.

Collectors: R Gnaneswaran

Distribution: Sri Lanka (Ibbagamua) and India

(Viraktamath, 1979)

Host plant :Atteriya (Murraya paniculata)

\section{Idioscopus Baker, 1915}

The genus Idioscopus was described by Baker (1915) with Idiocerus clypealis Lethierry as the type species and then was redefined by Maldonado Capriles (1964) who transferred several species of Idiocerus described from Oriental region, to this genus. Freytag and Knight (1966) described 7 species from Madagascar and differentiated the Idioscopus from Idiocerus by the presence of a sub apical spine on the hind femur in addition to the two apical one. So far the genus comprises nearly 30 species worldwide, with 20 out of them from the Indian subcontinent (Viraktamath, (1979), includes I. clypealis, I. nagpurensis and I. nitidulus, known to occur in Sri Lanka (Gnaneswaran, et al., 2007).

During this study, one species namely I. unimaculatus ( Melicher) was collected at Pereadeniya, after its first report by Melicher, 1903

Idioscopus unimaculatus (Melichar) (Plate:1-d, 4 and Plate:2- d,4)

Idiocerus unimaculatus Melichar 1903: 149

Pedioscopus unimaculatus (Melichar) Baker, 1915:318

"Pedioscopuis “ unimaculatus ( Melichar), Maldonado Capriles, 1972:542

Colouration: Colours as described by Melichar (1903). (Plate: 1-d,4; Plate:2-d,4)

General colour light brownish yellow. face convexed, light yellow without any marks, ocelli small clear; antennae pale yellow; eyes large, grayish pale yellow. Pronotum pale yellow, no marks, scutellum wax yellow with a large round black dot occupying the intermediate space between the base and the transverse line; tegmina brownish with paler veins, an opaque greenish yellow mark at base of clavus. Outer apical cell triangular; a dark brown spot at the tip of the $2^{\text {nd }}$ apical cell; hind wings hyaline with brown veins; ventral body pale yellow; dorsal body dark brown. Legs pale yellow; at inside end of the front tibiae in males with distinct black dot, setate arising from this area dark brown; but in female either pale dot or no mark at the end of the front tibia; all the claws brown.

Structure: Vertex and face dorsad of ocelli transversely striate, rest of face shagreen. Vertex with inter ocular distance 4 times as wide as its median length. Face convex, wider than long. Labium reaching anterior extremities of hind coxae. Clypellus with wide apex and lateral margins concave. Pronotum is shagreen, 2.19 times wider than its length and 2.6 times longer than the vertex, posterior margin 
slightly concave at the middle. Scutellum shagreen, slightly longer than pronotum (x 1.2). Male eighth sternite with convex hind margin. Forewing with 4 apical and 3 anteapical cells, venation as in plate1-4. Claval veins and basal parts of other veins lined with two rows of prominent pits. Hind femoral spinulation $2+1$ but in some female, left femur with ill developed spines as $2+0$.

Male genitalia: Pygofer is elongate. Sub genital plates elongate narrow basally than remainder, bearing long hairlike setae at dorsal and ventral margin up to the apex. Anal collar process bluntly bifurcate. Style strongly arched apophysis almost twice as long as the part anterior to articulation with connective: apophysis slightly narrowed caudally with crenulated ventral margin and with a sub apical tooth. Connective as about as wide as long aedeagus with a well-developed dorsal apodeme reaching nearly $1 / 3$ length of shaft. A pair of sub apical long filamentous processes with serrated outer margin, extending beyond the base of the aedeagus. Shaft narrow with rounded apex. Gonopore at the $1 / 3$ of the shaft from the apex.

Female genitalia: Seventh sternum with anterior margin convex. Ovipositor exceeding pygofers, second pair of gonophysis with slightly developed denticles restricted to $1 / 3$ th of its length.

Measurements: male $1-3.96 \pm 0.04 \mathrm{~mm}$; female 1$4.16 \pm 0.02 \mathrm{~mm}$

Material examined: SRI LANKA MCWZ: 6 males, 3 females, Peradeniya, 14.iii.2006;3 males , 3 females, Peradeniya 29.i.2007; 5 males, 3 females, Peradeniya, 12.xiii.2008;30 males, 41 females, Peradeniya, 12.i.2009; 2 males, 5 females, Peradeniya, 14.iii.2020; 6 males, 11 females 28.i.2021.

Host plants : Semecarpus coriacea (Anacardiaceae)

Collectors: RGnaneswaran, UGLTGunawardhana

Distribution : Sri Lanka (Peradeniya)

Remarks: Melichar (1903) described the species in the genus Idiocerus Lewis. Later Baker (1915) moved it to the genus Pedioscopus. But Maldonado Capriles (1972) did not accept this transfer and retained the species provisionally in Pedioscopus for further revision. The species has all the characters of the genus Idioscopus and is transferred to this genus. In this study, large number of males and females of this species were collected from its type locality (Peradeniya) in Sri Lanka after a century of its description by Melichar (1903).

The species can readily be recognized by the immaculate face and large round spot on scutellum and lemon yellow spot on forewing clavus. It externally resembles Idioscopus spectabilis Viraktamath from India, but differs in coloration and structure of aedeagus.

\section{Amritodus Anufriev 1970}

Genus Amritodus was established by Anufriev (1970), with Idiocerus atkinsoni (Lethierry) as its type species. Four species of Amritodus have been described from Indian subcontinent and they all are serious pests of mango (Viraktamath, 1989). They are A.atkinsoni (Lethierry) Anufriev (1970), A.brevistylus Viraktamath (1976); A saeedi Ahamed et al., (1980) in Pakistan, A.brevis Viraktamath (1987). Of those, presence of two species such as $A$. atkinsoni and $A$. brevistylus, have already been reported from Sri Lanka (Melichar, 1903, Wijesekara and Menike, 1997) respectively. However, A. atkinsoni was not found in any sites that surveyed during this study. A. brevistylus was recorded throughout the country along with Idioscopus species (Gnaneswaran, et. al., 2007)

\section{E. Periacerus Viraktamath and Parvathi 2002}

The genus Periocerus was described by Viraktamath and Parvathi (2002) with Idiosopus lalithae Viraktamath as the type species. Two other species: Periacerus lankensis Viraktamath and Parvathi (Sri Lanka) and P.bidentatus Viraktamath and Parvathi (India) were also described by same authors. No species in this genus were collected during this study.

\section{DISCUSSION}

Idiocerini feed and breed on a wide variety of trees and shrubs. Like other cicadellids, when they occur in large numbers through sucking sap from tender leaves, shoots and flowers. In addition, they affect indirectly by excretion of honeydew that enhance the growth of shooty mold on leaves and fruits (Viraktamath, 1989). Only one species, Idiocerus populi (L.), has been recorded as a vector of an unknown organism that produces 'witches broom disease' on Poplar (Webb, 1983).

I. nagpurensis is more prevalent in the Dry zone area of Sri Lanka than the wet zone and associated with many other tree crops apart from mango (Gnaneswaran, et.al., 2007). Both males and females of Jogocerus freytagi Viraktamath -one of the two species reported from indian subcontinent, found on Murraya paniculata (Rutaceae) in intermediate zone. Idioscopus unimaculatus Melichar (1903) found only in its type locality- Peradeniya, after a century of its description. It breeds on Semecarpus coriacea belongs to Anacardiaceae and prevail throughout the year. The adults were also found on non-breeding host, Mesua nagassarium in the same location but not on Mango. Morphological study of male and female genitalia of Amritodus genus collected from different ecological locations confirmed the presence of A. brevistylus along with Idioscopus clypealis and Idioscopus nitidulus species but not A.atkinsoni in anywhere. 


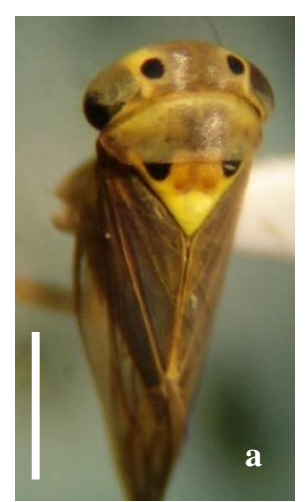

Idiocerusclypealis Lethierry

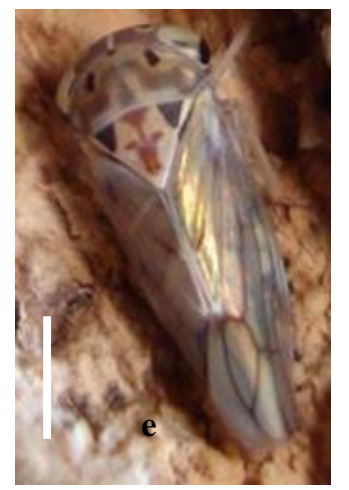

Amritodus brevistylus Viraktamath,

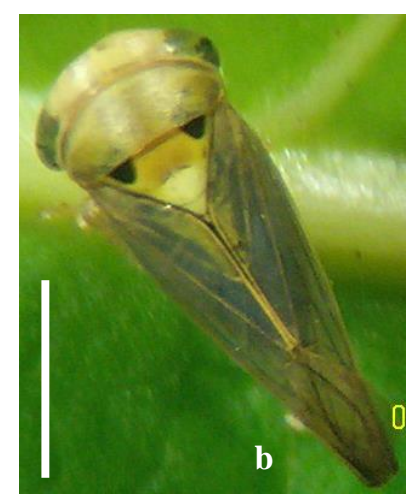

Idioscopus nagpurensis (Pruthi)

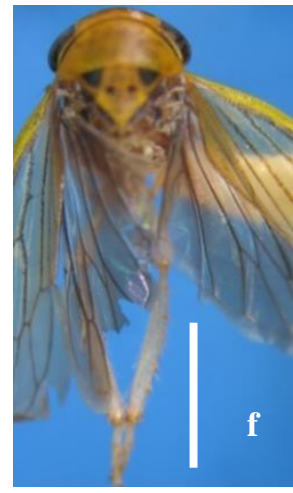

Busoniomimus manjunathi Viraktamath \& Viraktamath,

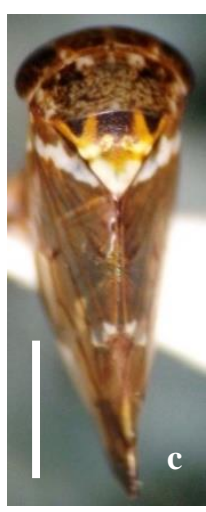

Idioscopusnitid ulus (Walker)

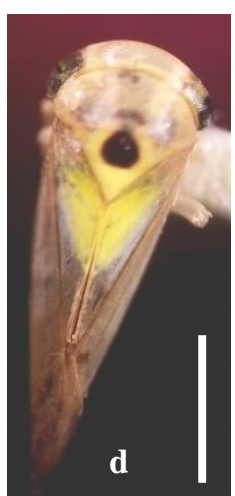

Idioscopus unimaculatus (Melichar)

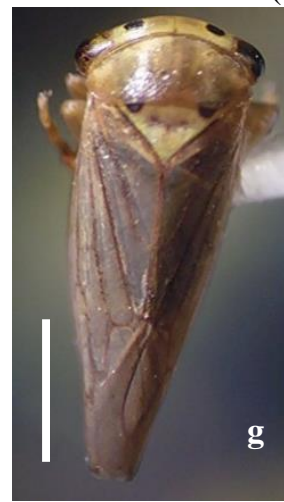

Jogocerus freytagi Viraktamath

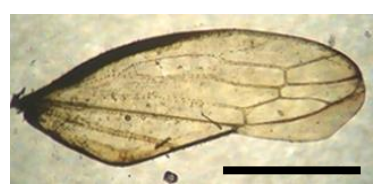

Fore wing of a

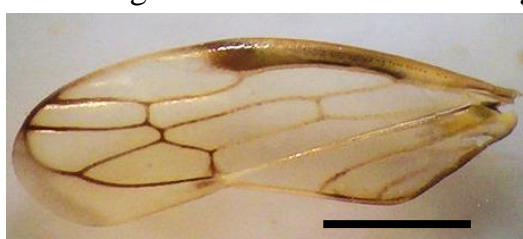

Fore wing of e

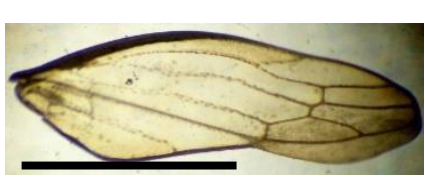

Fore wing of $b$

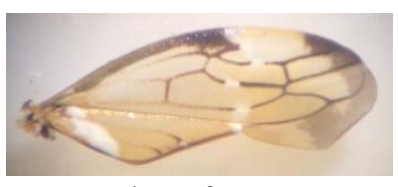

Fore wing of $\mathrm{c}$

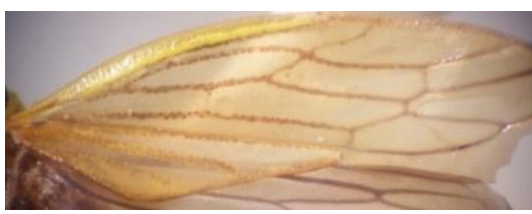

forewing of $f$

with two sub-apical cells

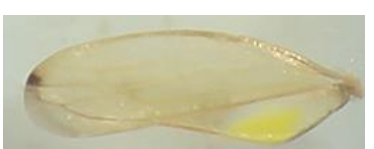

Fore wing of $\mathrm{d}$

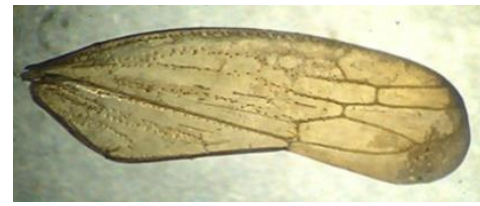

Fore wing of $\mathrm{g}$

Plate 1:

Habitus and forewing of species of Idiocerini leafhoppers recorded in Sri Lanka Scale $=0.05 \mathrm{~mm}$ 


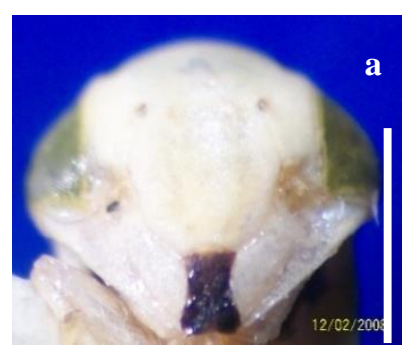

Idioscopusclypealis Lethierry

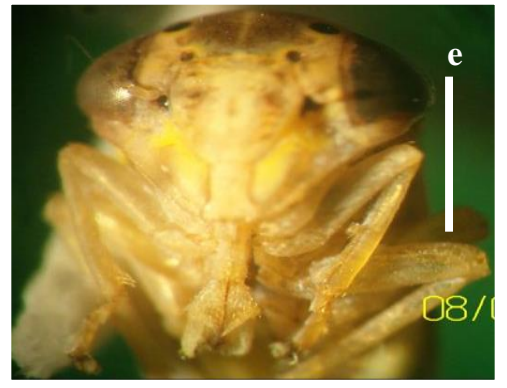

Amritodus brevistylus Viraktamath,

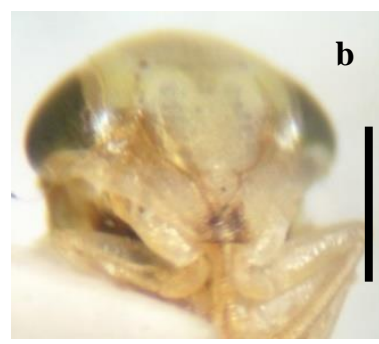

Idioscopus nagpurensis (Pruthi)

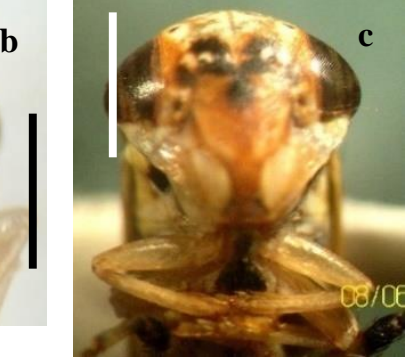

Idioscopusnitidulus (Walker)

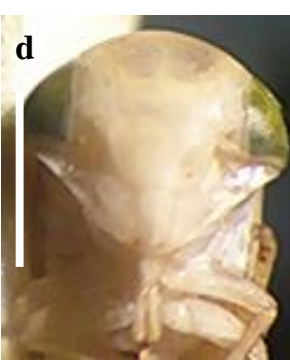

Idioscopus unimaculatus (Melichar)

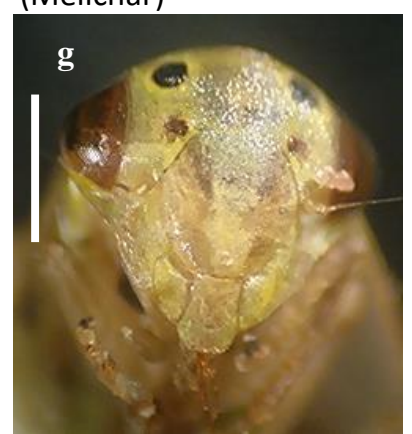

Jogocerus freytagi Viraktamath

Busoniomimus manjunathi Viraktamath \& Viraktamath,
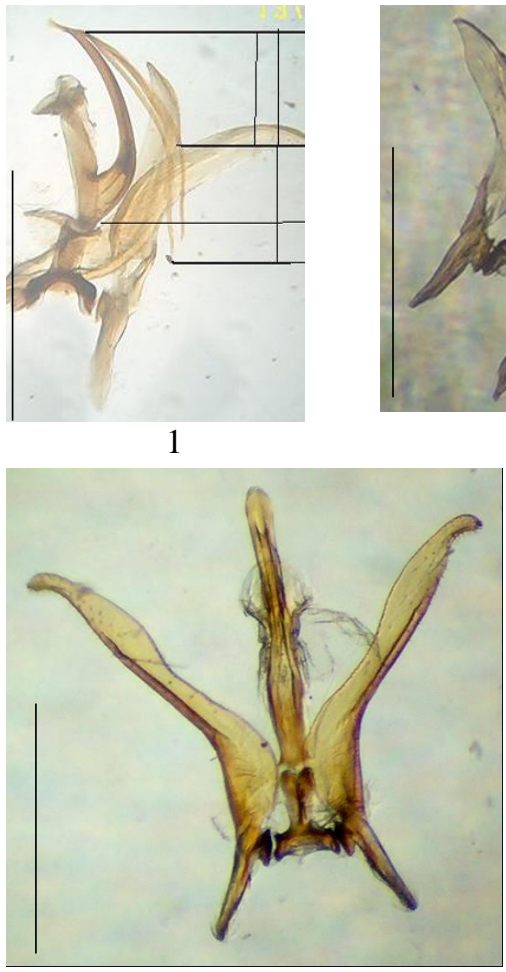

5

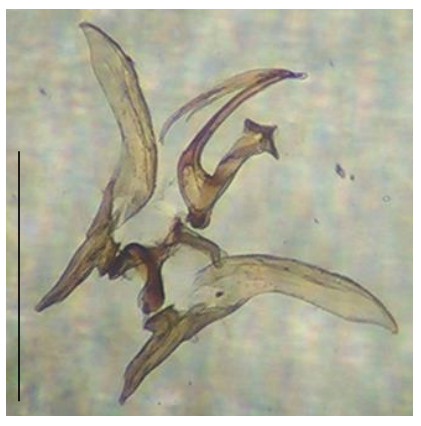

2

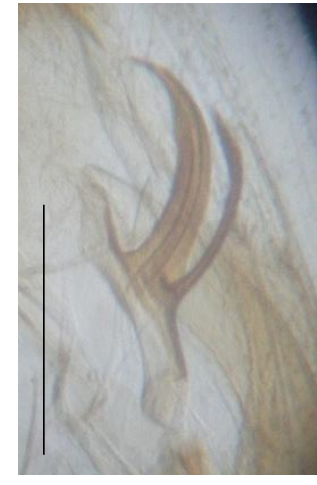

6

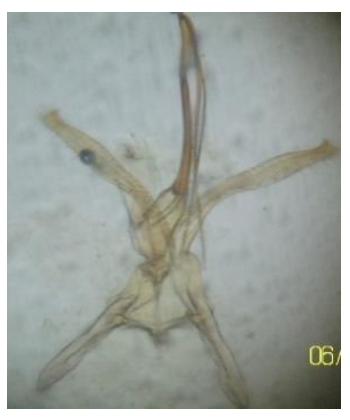

3

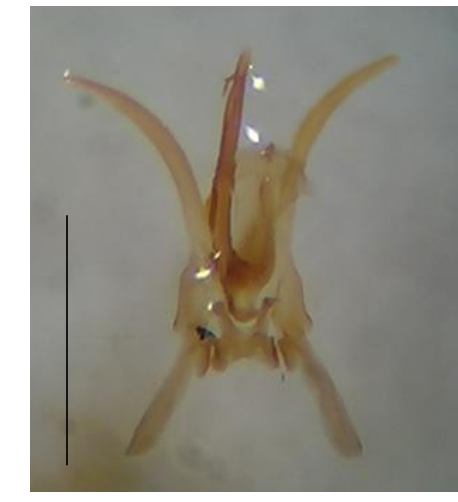

7

Plate 2: Face and male genitalia of species of Idiocerini leafhoppers recorded in Sri Lanka. $\mathrm{a}-\mathrm{g}$ : face of male scale $=0.05 \mathrm{~mm} ; 1-7$ Genitalia of male - Scale $=0.005 \mathrm{~mm}$

a,1: Idioscopus clypealis Lethierry b,2:Idioscopus nagpurensis (Pruthi) c,3: Idioscopus nitidulus (Walker) d,4 .Idioscopus unimaculatus (Melichar)e,5: Amritodus brevistylus Viraktamath, 6,f: Busoniomimus manjunathi Viraktamath \& Viraktamath, 7,g: Jogocerus freytagi Viraktamath 


\section{REFERENCES}

Baker, C.P. (1915). Studies in Philippine Jassoidea, IV: The Idiocerini of the Philippines. The Phili. J. Sci. 10 (6): 317 342 .

Distant, W.L. (1908). Rhynchota - Homoptera; The Fauna of British India including Ceylon and Burma. Taylor and Francis Ltd. London. iv: Pp.501.

Distant, W.L. (1916). The fauna of British India - Ceylon and Buma. Rhynchota, Vol VI -Homoptera, Taylor and Francis, London. Appendix. viii, Pp.248.

Distant, W.L. (1918). The fauna of British India - Ceylon and Burma. Rhynchota Vol VII -Heteroptera, Taylor and Francis, London. Appendix. viii, Pp.210.

Fletcher, M.J. and Dangerfield, P.C. (2002). Idioscopus clypealis (Lethierry), a second new leafhopper pest of mango in Australia Hemiptera: (Cicadellidae: Idiocerinae). Australion J. Entomol. 41:35 - 38.

Freytag, P.H. and Knight, W.J. (1966). The Idiocerinae of Madagascar (Hom.:Cicadellidae). Annales de la Societe Entomologique de France (N.S), 2:75-103.

Gnaneswaran, R., Hemachandra, K.S., Viraktamath, C.A., Ahangama, D., Wijayagunasekara, H.N.P. \& Wahundeniya, I. (2007) Idioscopus nagpurensis (Pruthi) (Hemiptera: Cicadellidae: Idiocerinae): a new member of mango leafhopper complex in Sri Lanka. Tropical Agricultural Research, 19, 78-90.

Gnaneswaran, R. (2014). "Ecology of Idiocerine Leafhoppers (Hemiptera: Cicadellidae: Idiocerinae)" of Sri Lanka" Presented in World Biodiversity Conference WBC -2014 held from 24th -27th November 2014, in Colombo, Sri Lanka. Abstract Proceeding Page 88.

Knight, W.J. (1965). Techniques for use in the identification of Leafhoppers (Homoptera: Cicadellidae). Entomologist Gazette 16: 129-136.

Maldonado-Capriles, J. 1964. Studies on Idiocerine leafhoppers II the Indian and Philippine species of Idiocerus and the genus Idioscopus. Proceedings of Entomoogical Society of Washington,66: 89-100.

Melichar, L. (1903). Homopteran Fauna von Ceylon. Verlag von Felix I., Damer Berlin. Pp. 248.

Viraktamath, C.A. (1979). Jogocerus GEN..NOV. and new species of Idiocerine Leafhoppers -from Southern India ( Homoptera: Cicadellide). Entomon, 4(1); 17-26.
Viraktamath, C.A. (1987). A revision of the idiocerine leafhopper genus Amritodus (Hemiptera: Cicadellidae) breeding on mango. Entomon..22 (2): 111-117.

Viraktamath, C.A. 1989. Auchenorrhyncha (Homoptera) associated with mango Mangifera indica L. Tropical Pest Management, 35: 431-434.

Viraktamath C.A. (2007). New genera and species of Idiocenine leafhoppers (Hemiptera: Cicadellidae) from India, Sri Lanka, and Myanmar. Biosystematica 1(1): 21-30.

Viraktamath, C. A. and Parvathi, C. (2002). Description of a new Idiocerine Genus Periacerus. Hemiptera: Cicadellidae, and two new species from India and Sri Lanka. J. Bombay Nat. History Soc. 99: 488 - 494.

Viraktamath, S. and Viraktamath, C.A. (1985). New species of Busoniomimus and Idioscopus (Homoptera, Cicadellidae: Idiocerinae) breeding on mango in south India. Entomon 10 (4): $305-311$.

Webb, M.D. (1983). Revision of the Australian Idiocerinae (Hemiptera:Homoptera: Cicadellidae).Australian Journal of Zoology Supplementary Series,31(92):1-147.

Xue, Q, C.H. Dietrich and Y.Zhang (2020). Phylogeny and classification of the leafhopper Subfamily Eurymelinae (Hemiptera: Cicadellidae) inferred from molecules and morphology Systematic Entomology, 45, 687-702.

Zhang. B and Li, Z., (2008) First report on the leafhopper genus Jogocerus Viraktamath ( Hemiptera: Cicadellidae) from China, with description of one new species Zootaxa, 1936:66-68. 